Artículos Resultado de la Investigación

\title{
Ventaja competitiva por diferenciación de la Zona Franca Internacional de Pereira
}

\section{Competitive advantage for differentiation of Pereira International Free Trade Zone}

\section{Ventagem competitiva para a diferenciação de Zona de Livre Comércio de Pereira}

\author{
Paola Andrea Echeverri Gutiérrez ${ }^{1}$ Sara María Gómez Caicedo \\ ${ }^{1}$ Universidad Libre Seccional Pereira, Colombia
}

\begin{abstract}
Resumen
La mejor forma de saber si una empresa está en el centro del éxito es mediante la determinación de su ventaja competitiva; para la Zona Franca Internacional de Pereira, plataforma de comercio exterior y proyecto de reciente puesta en marcha, es importante identificar esta, de manera que pueda desarrollar estrategias de entrada y permanencia en el mercado. En esta investigación se realizó el análisis de las cinco fuerzas del sector de las zonas francas, se definió la cadena de valor de la Zona Franca Internacional de Pereira, finalmente se determinaron los factores que inciden en su ventaja competitiva.
\end{abstract}

Palabras clave: Ventaja competitiva, Diferenciación, Zonas francas

\begin{abstract}
The best way to know if a company is at the heart of success is by determining its competitive advantage. For Pereira International Free Trade Zone, foreign trade platform and recent project implementation, it is important to identify its competitive advantage, so it can develop strategies for entering and staying in the market. In this research, an analysis of the five forces industry free zones was performed, the value chain of the Pereira International Free Trade Zone was defined, finally the factors that influence their competitive advantage was determined.
\end{abstract}

Key words: Competitive advantage, Differentiation, Free trade zones

\begin{abstract}
Resumo
A melhor maneira de saber se uma empresa está no coração do sucesso é, determinando a sua vantagem competitiva. Por Zona de Livre Comércio de Pereira, plataforma de comércio exterior e implementação recente projeto, é importante identificar a sua vantagem competitiva, para que possa desenvolver estratégias para entrar e permanecer no mercado. Nesta pesquisa, uma análise das zonas francas industriais cinco forças foi realizada, a cadeia de valor da Zona de Livre Comércio de Pereira definido, finalmente os fatores que influenciam a sua vantagem competitiva é determinado.
\end{abstract}

Palavras-chave: Vantagem Competitiva, Diferenciação, Zonas de Livre Comércio

Correspondencia: Paola Andrea Echeverri Gutiérrez. Universidad Libre Seccional Pereira. paecheverri@unilibrepereira.edu.co 


\section{Introducción}

Las zonas francas en Colombia están reglamentadas por la ley 1004 de 2005, la cual las define como "el área geográfica delimitada dentro del territorio nacional, en donde se desarrollan actividades industriales de bienes y de servicios, o actividades comerciales, bajo una normatividad especial en materia tributaria, aduanera y de comercio exterior" (Congreso de Colombia, p. 1). Las primeras zonas francas en el país fueron en la Costa Atlántica y la Costa Pacífica, declaradas como puertos libres destinados a la importación y exportación de mercancías.

Las zonas francas, hoy en día, son un mecanismo de fomento a la competitividad de un país, ya que permiten la creación de empleos directos e indirectos, el desarrollo de nuevas tecnologías, la innovación en procesos industriales, la generación de economías de escala, la atracción de capital extranjero, el fortalecimiento empresarial en las regiones, así como la agilización de los procesos de importación y exportación, lo que propicia facilidad, un mejor funcionamiento del comercio exterior y crecimiento de la economía nacional.

La búsqueda de una ventaja competitiva, proporciona a la empresa un conocimiento profundo de sus gestiones internas, procesos y estrategias, así como encontrar aquellas actividades fuentes de valor, que generan mayor rentabilidad. De ahí que la competitividad permite establecer una posición provechosa en el mercado, además de lograr la apertura de nuevos canales, generar crecimiento sostenido y alcanzar la supervivencia en un entorno de constante cambio.

Según la página web de la Zona Franca Internacional de Pereira, esta es:

Una plataforma integral de comercio exterior que permite la implementación de proyectos industriales a gran escala, el intercambio comercial con los más importantes mercados del mundo, el desarrollo logístico nacional e internacional, el movimiento de mercancías por vía terrestre, ferroviario, marítima, fluvial (a largo plazo) y la prestación de servicios en los diferentes sectores económicos. (Página web de Zona Franca de Pereira, 2013).

Para resolver el objetivo general de esta investigación se llevó a cabo un análisis para definir la competitividad del sector de las zonas francas en Colombia, se determinaron las actividades (primarias y de apoyo) que generan valor en la Zona Franca Internacional de Pereira y que son fuente de diferenciación, finalmente se establecieron los factores que inciden en la ventaja competitiva de la Zona Franca Internacional de Pereira.

El producto de esta investigación le servirá a la Zona Franca Internacional de Pereira como marco de referencia para conocer su ventaja competitiva, ya que hasta el momento los estudios analizados no se han enfocado en conocer la ventaja competitiva de las zonas francas como empresa. Entre estos estudios se encuentran: "Plan de negocios para la creación de la Zona Franca Permanente de la Sabana", (Alvarado y Méndez, 2008), "Plan de negocio para el montaje de una zona franca permanente especial en servicios de salud" (Fernández y Mejía, 2010), "Las implicaciones de la política tributaria en las zonas francas de Colombia" (Correa, Bustamante y Toro, 2006), entre otros.

\section{Metodología}

Este estudio comprende una descripción e interpretación de los fenómenos del tema de investigación por medio de la recolección y análisis de información, aplicando mecanismos de observación, revisión bibliográfica, revisión de documentos y entrevistas a expertos, que condujeron a la construcción de instrumentos de medición cuyos resultados permitieron dar solución al problema de investigación: establecer la ventaja competitiva por diferenciación de la Zona Franca Internacional de Pereira.

Se realizó un análisis holístico de los aspectos que, según los postulados de Michael Porter y la Teoría Sistémica de la Competitividad, interfieren en el establecimiento de una ventaja competitiva por diferenciación; a través de un método deductivo, “(...)que va de lo general a 10 particular, de lo universal a lo individual" (Ortíz y García, 2012, p. 64). Se partió de un marco teórico general y se constituyeron los resultados por medio de la aplicación de una serie de instrumentos que sirvieron para establecer, desde un punto de vista cualitativo, la ventaja competitiva de una empresa o sector determinado.

Este estudio se inició con el análisis de las cinco fuerzas del sector, según el modelo de Michael Porter, que tiene como finalidad determinar las 
principales características del entorno, que comprenden la amenaza de entrada de nuevos competidores, la rivalidad existente entre estos, la amenaza de productos o servicios sustitutos, el poder de negociación de los compradores y de los proveedores. Estos resultados son relevantes en la determinación del atractivo de un sector.

Porter (2008), aseguró que:

La comprensión de las fuerzas competitivas y sus causas subyacentes, revela los orígenes de la rentabilidad actual de un sector y brinda un marco para anticiparse a la competencia e influir en ella ( $y$ en la rentabilidad) en el largo plazo. ( $p$. 61)

En primer lugar, la amenaza de nuevos competidores supone una de las fuerzas más importantes, en esta se establecen las barreras de entrada a los nuevos competidores que deseen llegar a la industria; mientras más alta sea la barrera, más difícil será para el nuevo competidor su entrada al sector, por lo cual lo hará en desventaja respecto aquellas empresas más antiguas.

Como segunda fuerza, la rivalidad entre competidores existentes define la competitividad general y la rentabilidad del sector. Esta rivalidad puede variar de acuerdo a cada sector, la cantidad de empresas pertenecientes a él y su tamaño. La competencia es permanente y para algunos competidores menos exitosos no representa ganancias significativas por lo que se ven en la necesidad de dimitir su participación en el sector; sin embargo, existen barreras de salida, las cuales mantienen a las empresas compitiendo en la industria.

Por su parte, la amenaza de productos o servicios sustitutos puede restarle atractivo al sector. Esto puede darse, en primer lugar, de acuerdo a la posición del comprador respecto al producto, si está dispuesto a cambiarlo, ya sea por precio, calidad o emocionalidad; en segundo lugar si el producto supone un mayor rendimiento o menor costo. Las empresas oferentes de estos productos deben ser consideradas como competidores potenciales.

Por último, el poder de negociación de los compradores y el poder de negociación de los proveedores pueden reducir la rentabilidad del sector; cada uno desea aumentar o bajar los precios, exigir mayor calidad y mejores servicios. La interacción de estas fuerzas se observa en la figura 1.

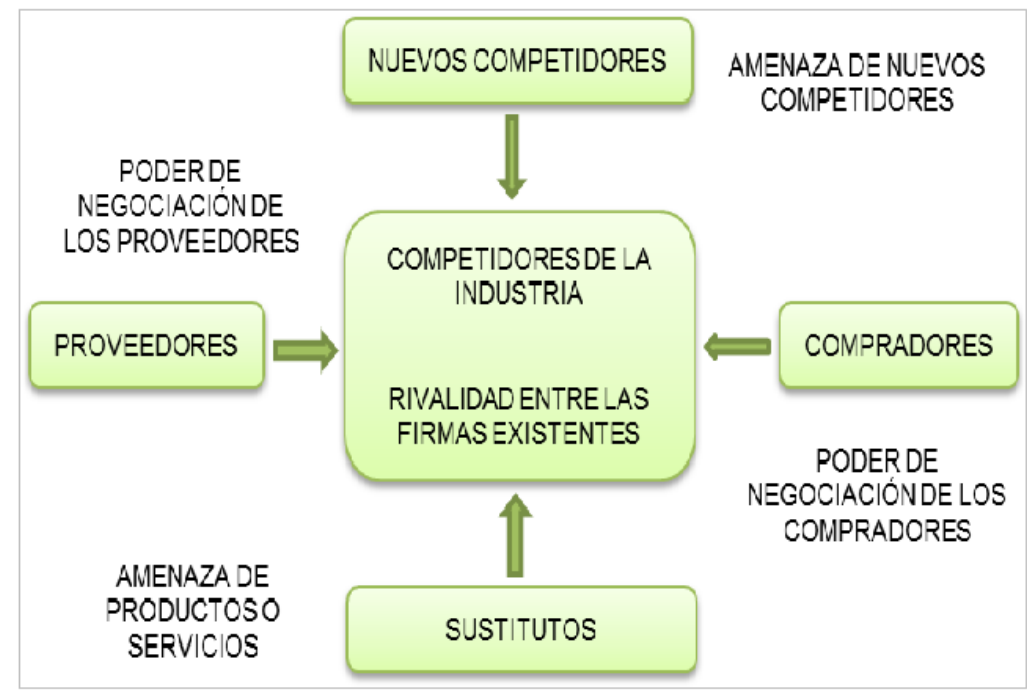

Figura 1. Las cinco fuerzas del sector de Michael Porter (1980, p. 4). 
Dentro de la identificación de la ventaja competitiva de una empresa es necesario definir la cadena de valor, de ahí que se establecieron las actividades generadoras de valor, que son fuente de diferenciación en la Zona Franca Internacional de Pereira.

La cadena de valor es:

Una herramienta básica para examinar de forma sistemática todas las actividades que una empresa desempeña y cómo interactúan. Disgrega a la empresa en sus actividades estratégicas relevantes para comprender el comportamiento de los costos y las fuentes de diferenciación existentes y potenciales. (Porter, 1991, p. 51).

Las actividades relacionadas directamente con la operación de la empresa y la elaboración del producto, son denominadas actividades primarias. Estas se enmarcan en cinco grupos: logística interna, operación, logística externa, mercadeo y ventas, y servicio.

Por otro lado, las actividades que sirven como soporte para llevar a cabo las actividades primarias, son las actividades de apoyo. Se concentran en: abastecimiento, desarrollo de tecnología, administración de recursos humanos e infraestructura de la empresa.

La importancia de la cadena de valor es la clasificación y organización gráfica de las actividades organizacionales, como se observa en la figura 2.

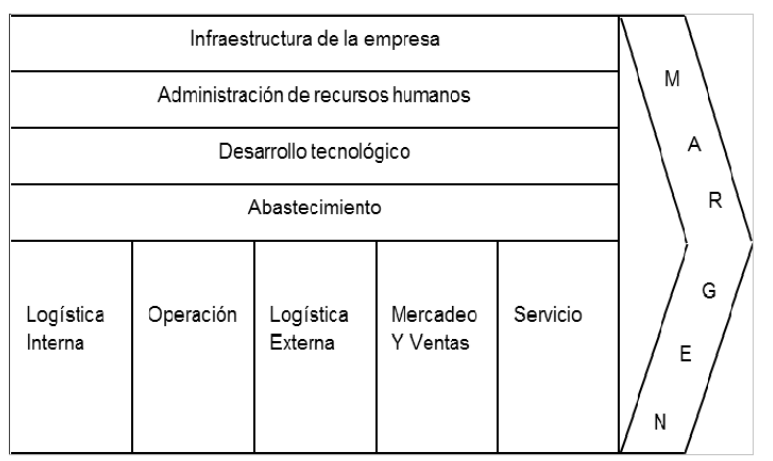

Figura 2. Cadena de valor. (Porter, M.,1991, p. 55).

Por último, se determinaron los factores que según la Teoría Sistémica de la Competitividad inciden en la ventaja competitiva de la Zona Franca Internacional de Pereira. La competitividad debe ser vista de manera integral. Una empresa no puede ser estudiada de forma independiente al ambiente que la rodea, puesto que este es parte fundamental en la determinación de la competitividad. Se llama ambiente no solo el sector al cual la empresa pertenece sino también a la región circundante así como el país. Es decir, como se afecta la competitividad de una empresa con el esfuerzo colectivo de integración de firmas (networking) para crear un entorno eficaz, asociado a un contexto macroeconómico estable y articulado con políticas gubernamentales de carácter económico, político, social y legal. Para definir el término de competitividad es mejor desde una perspectiva sistémica ya que la interacción de los niveles permite la creación de ventajas competitivas.

Al respecto, algunos autores plantean:

Se prefiere el concepto de 'competitividad sistémica' para enfatizar los siguientes aspectos: la competitividad de la economía se basa en medidas engranadas entre sí que apuntan a objetivos concretos desde cuatro niveles del sistema (meta, macro, micro y meso), y se basa también en un concepto pluridimensional de conducción que se compone de competencia, diálogo y toma conjunta de decisiones y que incluye a los grupos importantes de actores. (Esser, Hillebrand, Messner y Meyer-Stamer, 2013).

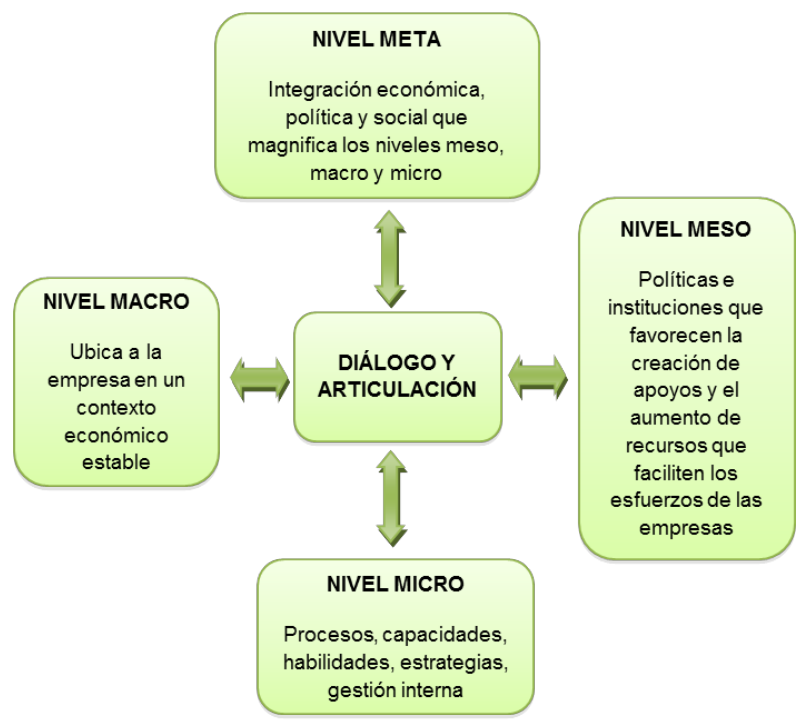

Figura 3. Competitividad sistémica. (Esser, K. Hillebrand, W. Messner, D. Meyer-Stamer, J., 2013) 
El nivel micro evalúa procesos, capacidades, habilidades, estrategias, gestión interna, precisamente cualquier elemento que le proporcione a la empresa un carácter diferenciador, además que genere eficiencia, flexibilidad, calidad y velocidad de reacción.

El análisis del nivel meso se refiere a las políticas específicas, instituciones, estructuras y redes de cooperación que favorecen la creación de apoyos, el aumento de los recursos que faciliten los esfuerzos de las empresas para favorecer su competitividad así como la de la industria que la envuelve.

En tercer lugar, el nivel macro ubica a la empresa en un contexto macroeconómico estable, apoyado por políticas fiscales, presupuestarias, monetarias y cambiarias armoniosas, que impulsen la productividad de los mercados y el crecimiento de la economía dentro del país.

Finalmente, dentro del marco del nivel meta se evidencia la integración económica, política y social orientada a generar autonomía, aprendizaje y una gran capacidad de respuesta por parte de las empresas ante los posibles cambios en el mercado. Igualmente magnifica los niveles meso, macro y micro, lo que se traduce en un refuerzo de la competitividad del país, es en este sentido que consecuentemente se da lugar a la determinación de la ventaja competitiva de la empresa.

\section{Resultados}

\section{Marco competitivo del sector de las zonas francas}

\section{Nuevos competidores.}

Gracias al constante crecimiento de la economía colombiana y a los incentivos que han propiciado la creación de nuevas zonas francas en el país, así como los beneficios que traen en materia de impuestos, comercio exterior, cambiarios y de inversión extranjera, según la Comisión Intersectorial de Zonas Francas (CIZF) se han declarado 33 zonas francas permanentes y 71 zonas francas permanentes especiales para un total de 104 zonas francas existentes en el país para el año 2012.

Las barreras de entrada se enumeran en el siguiente cuadro: 


\begin{tabular}{|c|c|}
\hline \multicolumn{2}{|c|}{ Barreras de Entrada del sector Zonas Francas } \\
\hline Barrera & Interpretación \\
\hline \multirow{7}{*}{$\begin{array}{l}\text { Políticas de gobierno: } \\
\text { Ley } 1004 \text { de } 2005\end{array}$} & $\begin{array}{l}\text { Área para funcionamiento no inferior a } 20 \text { hectáreas. } \\
\text { Debe mostrar títulos de propiedad de los terrenos sobre } \\
\text { los que se desarrollará físicamente el proyecto de la } \\
\text { Zona Franca Permanente, con exhibición de plano } \\
\text { topográfico y fotográfico. }\end{array}$ \\
\hline & Constituir persona jurídica domiciliada en el país. \\
\hline & $\begin{array}{l}\text { Presentar hojas de vida de la totalidad del personal } \\
\text { directivo yde los representantes legales }\end{array}$ \\
\hline & $\begin{array}{l}\text { Estudios de factibilidad técnica, económica, financiera y } \\
\text { de mercado que demues tren la viabilidad del objetivo }\end{array}$ \\
\hline & $\begin{array}{l}\text { Plan Maestro de Desarrollo General de la Zona Franca } \\
\text { aprobado por la Comisión Intersectorial de Zonas } \\
\text { Francas }\end{array}$ \\
\hline & $\begin{array}{l}\text { Crear ciento cincuenta (150) nuevos empleos directos y } \\
\text { formales. }\end{array}$ \\
\hline & $\begin{array}{l}\text { Cuando se pretenda la declaratoria de existencia de } \\
\text { Zonas Francas Permanentes Especiales dedicadas a la } \\
\text { prestación de servicios de salud, el cincuenta por ciento } \\
(50 \%) \text { de los nuevos empleos deberán ser directos y } \\
\text { formales y el cincuenta por ciento }(50 \%) \text { restante podrá } \\
\text { ser de empleos vinculados. }\end{array}$ \\
\hline \multirow[b]{2}{*}{$\begin{array}{l}\text { Requerimientos } \\
\text { capital }\end{array}$} & $\begin{array}{l}\text { Inversión igual o superior a cuarenta y seis mil salarios } \\
\text { mínimos mensuales legales vigentes ( } 46.000 \text { S.M.M.LV.) }\end{array}$ \\
\hline & $\begin{array}{l}\text { Tratándose de proyectos agroindustriales el monto de la } \\
\text { inversión deberá corresponder a setenta y cinco mil } \\
\text { salarios mínimos mensuales legales vigentes (75.000 } \\
\text { S.M.M.L.V) o la vinculación de quinientos (500) o más } \\
\text { trabajadores. }\end{array}$ \\
\hline \multirow{6}{*}{$\begin{array}{l}\text { Ventajas de } \\
\text { actores } \\
\text { establecidos }\end{array}$} & $\begin{array}{l}\text { Zonas Francas con mayor antigüedad han desarrollado } \\
\text { curvas de aprendizaje que les permiten reducir costos }\end{array}$ \\
\hline & $\begin{array}{l}\text { Certificaciones ISO 9001:2008, ISO 28000:2007 y } \\
\text { Certificación Código BASC (Business Alliance For Secure } \\
\text { Commerce) }\end{array}$ \\
\hline & $\begin{array}{l}\text { Software E-Franco especializado en el manejo de las } \\
\text { operaciones de Comercio Exterior }\end{array}$ \\
\hline & $\begin{array}{l}\text { Licenciamiento de uso del programa PICIZ Web } \\
\text { (Software integral para el control de sistemas de } \\
\text { información de las zonas de libre comercio) }\end{array}$ \\
\hline & $\begin{array}{l}\text { Software SIZFRA para manejo de zonas francas, gira } \\
\text { alrededor del Formulario de Movimiento de Mercancías } \\
\text { (FMM) utilizado para registrar la entrada y salida de } \\
\text { mercancías }\end{array}$ \\
\hline & $\begin{array}{l}\text { Ubicación geográfica privilegiada (acceso a canales de } \\
\text { distribución internacionales). }\end{array}$ \\
\hline Infraes tructura & $\begin{array}{l}\text { Creación de parques industriales competitivos, con la } \\
\text { infraestructura física adecuada para la facilitación de } \\
\text { procesos industriales yla prestación de servicios. }\end{array}$ \\
\hline $\begin{array}{l}\text { Restricciones } \\
\text { Gubernamentales }\end{array}$ & $\begin{array}{l}\text { Se limitará la creación de zonas francas } \\
\text { uniempresariales productoras de bienes, salvo las } \\
\text { peticiones ya radicadas. }\end{array}$ \\
\hline
\end{tabular}

Cuadro 1. Barreras de entrada del sector zonas francas. (Creado por las autoras). 
Respecto al tema de instalar nuevas zonas francas en Colombia, enfatizó Edgar Orlando Martínez, director ejecutivo de la Cámara de Zonas Francas de la ANDI "...que desde el gobierno nacional se determinó que por el momento no se aprobarían nuevas zonas, hasta que las existentes en el país no se desarrollen completamente y no tengan el nivel de ocupación óptimo"(Pahón, 2013).

\section{Competidores de la industria.}

La ciudad de Bogotá, que está enmarcada por el departamento de Cundinamarca, presenta el mayor número de zonas francas en el país, con nueve zonas francas permanentes (ZFP) en los sectores industrial, servicios, así como servicios de salud y 14 zonas francas permanentes especiales (ZFPE) en los ámbitos industrial, call center, servicios, servicios de salud y biocombustibles; esto se debe principalmente a que la capital del país es un gran centro industrial y de negocios, con la potencia para competir con las grandes ciudades del mundo.

En segundo lugar, Bolívar posee seis ZFP industriales y de servicios, diez ZFPE en servicios de salud, industria, biocombustible, al igual que de servicios portuarios, como consecuencia de la cercanía al puerto de Cartagena. En tercer lugar, se encuentran Valle del Cauca y Atlántico, el primero posee tres ZFP industriales y seis ZFPE industriales, agroindustriales y de servicios portuarios, el segundo cuenta con cuatro ZFP relacionadas con el sector industrial, cinco ZFPE de generación de energía, servicios portuarios, servicios de salud y call center. En el siguiente lugar, se incluyen Antioquia con tres ZFP en el sector agroindustrial e industrial, así como cinco ZFPE industriales y de servicios de salud. Magdalena tiene cuatro ZFP en la parte industrial, cuatro ZFPE dedicadas a los servicios portuarios, biocombustibles, así como agroindustrial. Cauca cuenta con dos ZFP industriales y seis ZFPE de los sectores industrial, call center y agroindustrial.

Santander se ubica en quinto lugar con una ZFP de ámbito industrial, cuatro ZFPE en biocombustibles y servicios de salud. Norte de Santander cuenta con una ZFP industrial, asimismo con dos ZFPE en servicios de salud. Caldas posee dos ZFP de los sectores agroindustrial e industrial, una ZFPE dedicada a los call centers. Risaralda tiene una ZFP industrial, dos ZFPE en servicios de salud, así como call center, al igual que Boyacá que posee una ZFP agroindustrial, dos ZFPE en el ámbito industrial y de biocombustibles. Huila cuenta con una ZFP industrial, dos ZFPE agroindustrial y de servicios de salud, ubicados en el sexto lugar.

Meta tiene tres ZFPE en el sector agroindustrial e industrial, lo que la ubica en el séptimo lugar. Nariño dos ZFPE en servicios de salud y agroindustrial, situándose en el octavo lugar. En noveno lugar, Tolima cuenta con una ZFP industrial y Cesar una ZFPE agroindustrial así como Córdoba una ZFPE industrial (ver gráfica $1)$.

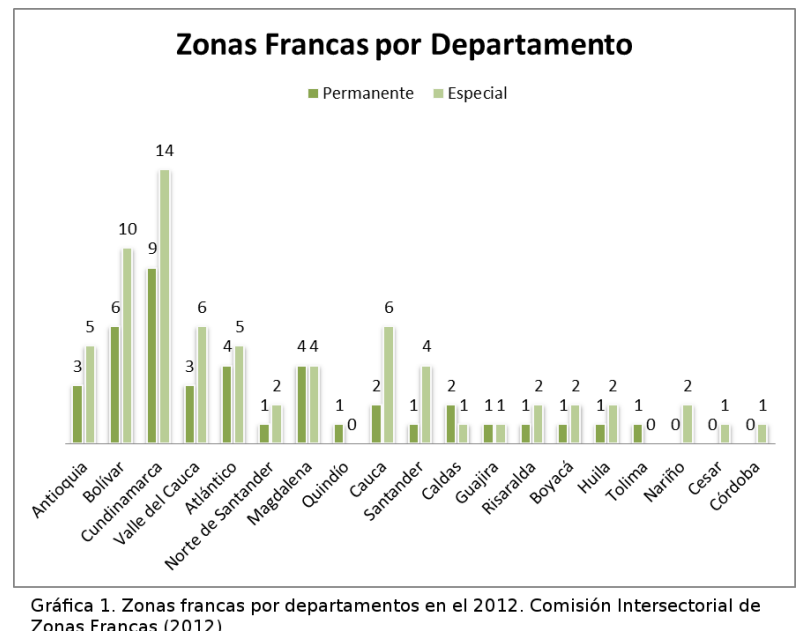

Zonas Francas (2012).

Las ZFP en su mayoría pertenecen al sector industrial, con 25 zonas declaradas, al igual que las ZFPE, con un total de 23, diversificadas estas últimas principalmente en la industria del papel y cemento. Abarca también desde cosméticos hasta placas de vidrio, partes y componentes, transformación de metales así como aceros e incluso procesamiento de químicos. Igualmente industrias de alimentos, en los cuales se incluyen frigoríficos, refinerías, bebidas. Las ZFPE que pertenecen al sector de servicios, concentradas especialmente en los servicios portuarios son 12 , las dedicadas a call centers son seis y las pertenecientes al sector de la salud son 11 . Adicionalmente, al sector de biocombustibles se dedican ocho ZFPE pero en la generación de energía se encuentra únicamente una ZFPE. Ahora bien, en el sector agroindustrial, se han declarado tres ZFP y ocho ZFPE (ver gráfica 2). 


\title{
Zonas Francas por Sector
}

\author{
- Permanente Especial
}

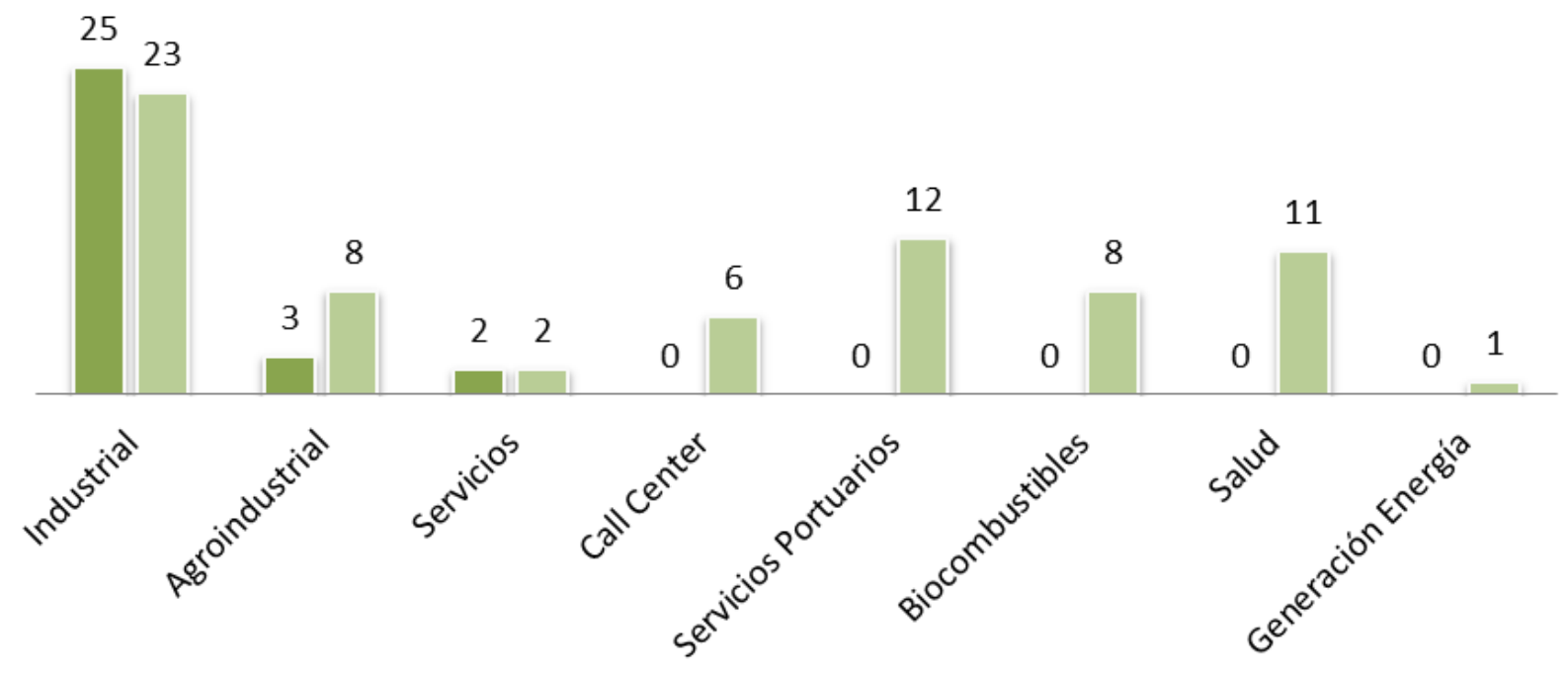

Gráfica 2. Zonas francas por sector. Comisión Intersectorial de Zonas Francas (2012).

\section{Sustitutos.}

La amenaza de productos sustitutos para el sector de zonas francas en Colombia no es una gran limitante para la competitividad, puesto que no existe otra que figura pueda realizar la misma función que las zonas francas. Sin embargo, si se analizan estas como plataformas logísticas, se consideran como sustitutos:

- Las Sociedades Portuarias: se consideran actividades portuarias la construcción, operación y administración de puertos, terminales portuarios, el manejo de cargue y descargue, llenado y vaciado de contenedores, embalaje, pesaje, cubicaje, operación de equipos portuarios y en general todas aquellas que se efectúen en los puertos y terminales portuarios.

- Los Operadores Logísticos: se encargan de ejecutar, así como prestar apoyo en todas las fases de la cadena de abastecimiento internacional de una empresa. Comprende actividades que van desde el aprovisionamiento, control de inventarios, transporte, almacenaje, hasta la entrega segura del producto al cliente final.

\section{Proveedores.}

Como proveedores de las zonas francas se encuentran las empresas que desempeñan las funciones de usuario operador. El régimen de zonas francas en Colombia define el usuario operador (UO) como "...la persona jurídica autorizada para dirigir, administrar, supervisar, promocionar y desarrollar una o varias Zonas Francas, así como para calificar a los usuarios que se instalen en estas." De ahí que posea la facultad de aumentar o disminuir la competitividad al igual que la rentabilidad del 
sector, puesto que puede influir de manera significativa en las empresas que se instalen en la zona franca permanente, controlando calidad, precios, al igual que la prestación del servicio.

\section{Compradores.}

Como compradores de las zonas francas, es decir, quienes acceden a los servicios ofrecidos por el usuario operador y disfrutan de los beneficios de las zonas francas son las empresas instaladas allí. El régimen franco en Colombia establece tres tipos de usuarios para las zonas francas permanentes:

EI usuario industrial de bienes (UIB) es la persona jurídica instalada, exclusivamente, en una o varias zonas francas, autorizada para producir, transformar o ensamblar bienes, mediante el procesamiento de materias primas 0 de productos semielaborados.

El usuario industrial de servicios (UIS) es la persona jurídica autorizada para desarrollar, exclusivamente, en una o varias zonas francas, entre otras, las siguientes actividades:

- Logística, transporte, manipulación, distribución, empaque, reempaque, envase, etiquetado o clasificación.

- Telecomunicaciones, sistemas de tecnología de la información para captura, procesamiento, almacenamiento y transmisión de datos, y organización, gestión u operación de bases de datos.

- Investigación científica y tecnológica.

- Asistencia médica, odontológica y en general de salud.
- Turismo.

- Reparación, limpieza o pruebas de calidad de bienes.

- Soporte técnico, mantenimiento y reparación de equipos, naves, aeronaves o maquinaria.

- Auditoría, administración, corretaje, consultoría o similares.

El usuario comercial (UC) es la persona jurídica autorizada para desarrollar actividades de mercadeo, comercialización, almacenamiento o conservación de bienes, en una o varias zonas francas. (El Diario del Otún, 2013)

\section{Cadena de valor de la Zona Franca Internacional de Pereira}

La definición de la cadena de valor como metodología para determinar y sostener ventajas competitivas fue desarrollada por Michael Porter, toma como base el principio de que la competitividad de una empresa radica en la descripción de sus actividades para encontrar las fuentes auténticas de diferenciación. La importancia de la cadena de valor es la clasificación y organización gráfica de las actividades organizacionales agrupadas en primarias y de apoyo.

Las actividades primarias que realiza la Zona Franca Internacional de Pereira impactan directamente en su función de usuario operador y en los usuarios industriales de bienes, de servicios y comerciales establecidos allí, representan la razón de ser la empresa (ver cuadro 2). Por su parte, las actividades de apoyo se relacionan de forma indirecta con estos usuarios y son las que proveen la infraestructura necesaria para ejecutar las actividades primarias (ver cuadro 3). 


\section{CADENA DE VALOR DE LA ZONA FRANCA INTERNACIONAL DE PEREIRA ACTIVIDADES DE APOYO}

\section{Infrestructura de la empresa}

"Creciendo Juntos", programa de responsabilidad social, busca apoyar a los ciudadanos del sector de Caimalito en materia de empleo y calidad de vida.

Mejores prácticas, la única zona franca del país reconocida con las mejores prácticas.

Certificación BASC, (Business Aliance for Secure Companies).

\section{Administración de Recursos Humanos}

Recursos Humanos, se encarga del bienestar social de los empleados de la compañía y apoya en los procesos de selección al Usuario Operador.

Reclutamiento y selección, apertura de convocatorias por medio de redes sociales y medios masivos de comunicación, se recogen, filtran y analizan las hojas de vida de acuerdo a los perfiles solicitados. Una vez seleccionadas las hojas de vida pasan a psicología para después proceder con la entrevista personal. Para las vacantes en la dirección se entregan las 3 opciones más acertadas y se hace la entrevista correspondiente. Ya para los usuarios finales (empresas ubicadas en zona franca), se entregan 25 opciones para su respectiva selección por parte de las mismas. Para los cargos operativos el proceso de selección es apoyado por el SENA.

Responsabilidad Social, se espera generar 15.000 empleos en la región.

\section{Desarrollo Teconológico}

Servicios de infraestructura, planta de tratamiento de agua potable, planta de tratamiento de aguas residuales, sub-estación eléctrica.

Te cnología y desarrollo, estructura física de última tecnología, para empresas con un desarrollo dinámico y exitoso.

Software, implementación de dos tipos de software, el primero es el exigido por el régimen franco el cual controla todas las operaciones de comercio exterior en línea con la DIAN, Apolo. El segundo consiste en un software logístico, que busca la velocidad y agilización en el movimiento de carga, mediante la implementación de básculas, cámaras en los vehículos y lectores de rostros de los conductores para evitar el contrabando.

\section{Abastecimiento}

Formatos de requerimientos, para cada uno de los usuarios calificados.

Control de inventarios, se maneja un proceso con mínimos y máximos.

Selección de proveedores, se requieren tres cotizaciones.

Evaluación de proveedores, se busca que los asociados, cumplan con las normas y estándares ambientales que maneja la Zona Franca Internacional de Pereira, para tal fin se realizan visitas dos veces al año, con el objetivo de comprobar el cumplimiento de los requerimientos.

Cuadro 2. Actividades de apoyo de la cadena de valor de la Zona Franca Internacional de Pereira. (Creado por las autoras) 


\section{CADENA DE VALOR DE LA ZONA FRANCA INTERNACIONAL DE PEREIRA ACTIVID ADES PRIMARIAS}

\begin{tabular}{|c|c|c|c|c|}
\hline Logí & & & Mero & \\
\hline \multirow{5}{*}{$\begin{array}{c}\text { Plan vial interno, } \\
\text { circuito de vías } \\
\text { internas de } 3.0 \\
\text { Km, diseñadas con } \\
\text { altas } \\
\text { especificaciones } \\
\text { para tráfico } \\
\text { pesado, amplias } \\
\text { vías entre } 10 \text { y } 17 \\
\text { metros, andenes } \\
\text { de } 4 \text { metros de } \\
\text { ancho y } 2 \text { metros } \\
\text { adicionales en } \\
\text { zonas verdes }\end{array}$} & $\begin{array}{c}\text { Usuario } \\
\text { Operador, } \\
\text { trámites aduaneros } \\
\text { simplificados, } \\
\text { aduana en sitio } \\
\end{array}$ & \multirow{2}{*}{$\begin{array}{c}\text { Transporte } \\
\text { terrestre, } \\
\text { consolidación de } \\
\text { un HUB Logístico } \\
\text { Nacional }\end{array}$} & \multirow{4}{*}{\begin{tabular}{|c|} 
Inteligencia de \\
mercados, se lleva \\
a cabo un análisis \\
de mercados de \\
cada cliente y de \\
cada proveedor, se \\
realiza una ficha \\
técnica con cifras, \\
se ofrecen \\
soluciones \\
económicas muy \\
competitivas \\
\end{tabular}} & $\begin{array}{c}\text { Operación } 24 \\
\text { horas, operación } \\
\text { continua sin cortes } \\
\text { ni interrupciones }\end{array}$ \\
\hline & \multirow{8}{*}{$\begin{array}{c}\text { Lotes y Bodegas, } \\
\text { áreas desde } 2.000 \\
\text { m2, los cuales } \\
\text { pueden ser } \\
\text { destinados para la } \\
\text { construcción de } \\
\text { bodegas, locales y } \\
\text { oficinas y/o para el } \\
\text { almacenamiento } \\
\text { de carga suelta, } \\
\text { carros y } \\
\text { maquinaria } \\
\text { pesada. Proyectos } \\
\text { de plantas } \\
\text { industriales desde } \\
1.550 \text { m2. Tres } \\
\text { edificios para Call } \\
\text { Centers, Contact } \\
\text { Centers, BPO's, } \\
\text { KPO's, ITO's, y } \\
\text { bodegas para Data } \\
\text { Centers }\end{array}$} & & & \\
\hline & & $\begin{array}{c}\text { Transporte } \\
\text { aéreo, hay en un }\end{array}$ & & $\begin{array}{l}\text { DIAN, oficinas en } \\
\text { sitio }\end{array}$ \\
\hline & & cuatro aeropuertos & & \multirow[b]{2}{*}{$\begin{array}{l}\text { Asesoría, en } \\
\text { régimen franco y } \\
\text { comercio exterior }\end{array}$} \\
\hline & & $\begin{array}{c}\text { Transporte } \\
\text { fluvial, cercanía al }\end{array}$ & $\begin{array}{l}\text { Sectores textil y } \\
\text { confecciones, }\end{array}$ & \\
\hline \multirow[t]{2}{*}{$\begin{array}{l}\text { Básculas, para el } \\
\text { control de entrada } \\
\text { y salida de } \\
\text { mercancías }\end{array}$} & & $\begin{array}{c}270 \mathrm{~km} \text { de } \\
\text { distancia de Puerto } \\
\text { Salgar }\end{array}$ & $\begin{array}{l}\text { servicios (BPO, } \\
\text { KPO, ITO) y } \\
\text { logístico, se }\end{array}$ & \multirow{3}{*}{$\begin{array}{l}\text { Capacitación, } \\
\text { alianza con el } \\
\text { SENA para } \\
\text { capacitar la mano } \\
\text { de obra de los } \\
\text { usuarios } \\
\text { calificados al } \\
\text { régimen franco } \\
\end{array}$} \\
\hline & & \multirow{3}{*}{$\begin{array}{c}\text { Transporte } \\
\text { férreo, proyecto } \\
\text { de ferrocarril desde } \\
\text { Buenaventura } \\
\text { hacia la Zona } \\
\text { Franca } \\
\text { Internacional de } \\
\text { Pereira }\end{array}$} & de cluster y & \\
\hline \multirow{2}{*}{$\begin{array}{l}\text { Patio de } \\
\text { contenedores, } \\
\text { Consolidación y } \\
\text { compensación de } \\
\text { carga industrial. } \\
\text { Procesos de } \\
\text { Cross Docking }\end{array}$} & & & $\begin{array}{l}\text { encadenamientos } \\
\text { productivos de } \\
\text { estos sectores } \\
\text { estratégicos }\end{array}$ & \\
\hline & & & $\begin{array}{c}\text { Bases de datos, } \\
\text { se compran bases } \\
\text { de datos a nivel } \\
\text { mundial }\end{array}$ & $\begin{array}{c}\text { Seguridad, } \\
\text { sistema integral de } \\
\text { seguridad } 24 / 7\end{array}$ \\
\hline
\end{tabular}

Cuadro 3. Actividades primarias de la cadena de valor de la Zona Franca Internacional de Pereira. (Creado por las autoras) 


\section{Factores determinantes de la competitividad}

La competitividad en las empresas es fruto de un esfuerzo que no depende únicamente de la gestión interna, es necesario desarrollar ventajas competitivas desde una perspectiva integral, en la cual se incluyan políticas de desarrollo a nivel meta y macro, la capacidad de la región a nivel meso, así como estrategias corporativas a nivel micro (ver cuadro 4).

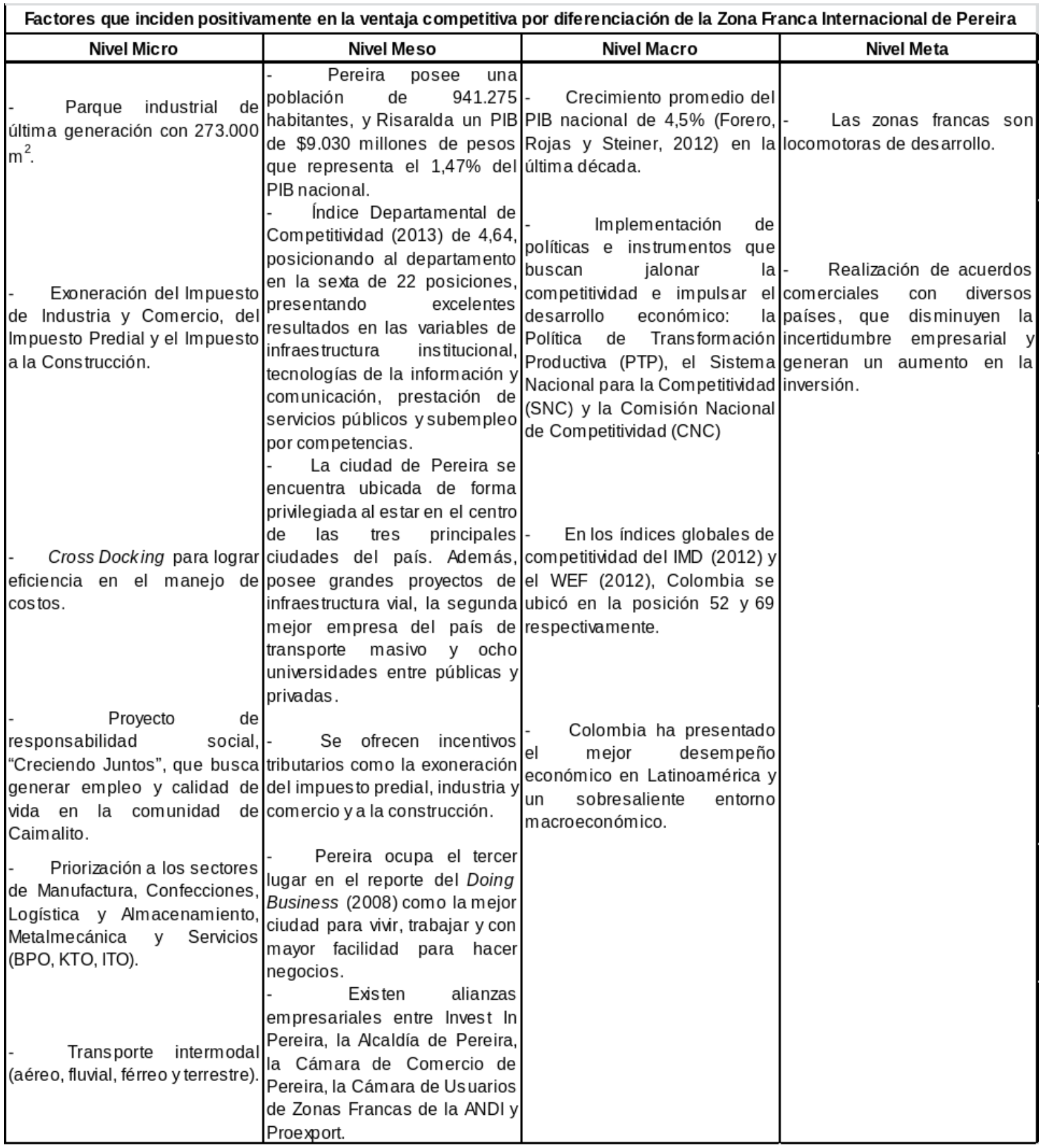

Cuadro 4. Factores que inciden positivamente en la ventaja competitiva por diferenciación de la Zona Franca Internacional de Pereira. (Creado por las autoras) 


\section{Conclusiones}

Efectuados los análisis correspondientes se obtuvieron las siguientes conclusiones:

Según el estudio de las cincos fuerzas de Michael Porter, el sector de las zonas francas en Colombia se perfila como una industria altamente competitiva; la fuerza de rivalidad entre competidores es la más significativa para este sector. Existen en el país 104 zonas francas permanentes y permanentes especiales declaradas por la Dirección de Impuestos y Aduanas Nacionales (DIAN), de las cuales 23 se encuentran en la región de Cundinamarca y Bogotá D.C., lugares establecidos como un gran centro logístico y de negocios, lo que permite que las zonas francas instaladas allí desarrollen rápidamente ventajas competitivas a la vez que obtienen rendimientos superiores. Dentro de los departamentos que puntean este ranking, se encuentran también Bolívar, Valle del Cauca y Atlántico; es importante resaltar que la competitividad de las zonas francas de estas regiones radica entre otros aspectos, en el aprovechamiento de su ubicación geoestratégica privilegiada dada la cercanía a los puertos de Cartagena, Buenaventura y Barranquilla, respectivamente. No obstante, departamentos como Tolima y Cesar solo poseen una zona franca, además en la región suroriental del país no se ha establecido ninguna. Las zonas francas en su mayoría pertenecen al sector industrial, agroindustrial y de servicios, concentradas estas últimas en servicios portuarios, call centers, así como salud.

Dentro de los servicios que ofrecen las zonas francas permanentes a sus usuarios se destacan los proyectos de responsabilidad social empresarial, la instalación de una ventanilla única de trámites, un sistema de divulgación de empleo, servicio médico y una ruta de transporte gratuita, como servicios fuentes de ventajas competitivas por diferenciación.

En cuanto a la amenaza de nuevos entrantes, segunda fuerza con mayor incidencia en el sector, los competidores que deseen ingresar deberán trabajar arduamente en contra de las barreras de entrada, se subrayan sobre todo el alto grado de inversión que debe ser igual o superior a cuarenta y seis mil salarios mínimos mensuales legales vigentes (46.000 S.M.M.LV.), las certificaciones ISO 9001:2008, ISO 28000:2007 y Certificación BASC (Business Alliance For Secure Commerce) que poseen los competidores más antiguos del sector y la obtención de un software especializado en el manejo de las operaciones de comercio exterior. Igualmente, no se aprobarán nuevas zonas francas en el país hasta que las ya declaradas no se desarrollen completamente y no tengan el nivel de ocupación óptimo. Por su parte, las fuerzas que presentan un menor impacto son el poder de negociación de los proveedores, el poder de negociación de los compradores y la amenaza de productos sustitutos, esta última la menos significativa.

De las actividades que realiza la Zona Franca Internacional de Pereira que son fuente de valor y de diferenciación se destaca su programa de responsabilidad social "Creciendo Juntos", que busca apoyar a los ciudadanos del sector de Caimalito en materia de empleo y calidad de vida, con la generación de 15.000 empleos y un proyecto de reurbanización, así como de reindustrialización de $2.000 .000 \mathrm{~m}^{2}$ en la región. Igualmente se encuentra con certificación BASC ( Business Aliance for Secure Companies), además es la única zona franca del país reconocida con las mejores prácticas. Adicional a esto, se ejecutan actividades de inteligencia de mercados, en las que se realizan análisis de los diferentes clientes y proveedores, se hacen fichas técnicas con cifras y se ofrecen soluciones económicas muy competitivas.

En cuanto a la innovación tecnológica, la Zona Franca Internacional de Pereira, además de obtener un software para el manejo de sus actividades de comercio exterior, ha desarrollado e implementado un software logístico, que busca la velocidad y agilización en el movimiento de carga.

Al desarrollar el método deductivo, se empleó la Teoría Sistémica de la Competitividad, con el fin de que a partir de una visión general se desglosaran los factores que inciden en la ventaja competitiva por diferenciación de la Zona Franca Internacional de Pereira. En el nivel micro se destaca la creación de un hub logístico con una ubicación geoestratégica privilegiada especializada en los sectores de manufactura, confecciones, logística y almacenamiento, metalmecánica y servicios (BPO, KTO, ITO). Además cuenta con servicios complementarios, proyectos de responsabilidad social empresarial y exoneración en el pago de impuestos municipales fuentes auténticas de diferenciación. 
En el nivel meso, es decir la capacidad de la industria y la región, se encontró en primera instancia que la ciudad de Pereira en el departamento de Risaralda posee condiciones competitivas para alojar la Zona Franca Internacional de Pereira, al tener una infraestructura institucional fuerte con altos niveles de transparencia, una gran red que permite el uso de tecnologías de la información y la comunicación, óptima cobertura de servicios públicos, así como un buen nivel de educación, ya que existen ocho universidades entre públicas y privadas que permiten generar empleo por subcompetencia. Asimismo, la empresa de transporte masivo Megabús es la segunda mejor calificada en el país y existen grandes proyectos viales como la Autopista del Café. No obstante, en las demás variables de infraestructura, colectividad, ejecución de alianzas público-privadas, políticas económicas y legales, así como la estabilidad jurídica se pueden encontrar limitaciones para el desarrollo de ventajas competitivas de las zonas francas.

Para el nivel macro se destaca la mejora en el entorno macroeconómico, el país ha ostentado en la última década un crecimiento económico promedio de $4,5 \%$, sin embargo existen circunstancias que han ralentizado dicho crecimiento, como los altos aranceles, cuyo promedio es de $8,3 \%$; el nivel de desempleo que alcanza el 8,5 \%, causado en parte por la desigualdad existente en el país y en otra parte, por los altos costos no salariales (CNS) que han desencadenado altos niveles de informalidad laboral, logrando la cifra de $61 \%$, la más alta de América Latina; además la estructura tributaria colombiana es en exceso compleja e ineficaz en el recaudo de los impuestos. Pese a esto, las zonas francas a través de la gestión del gobierno y la implementación de políticas que buscan el incremento de la competitividad, como la Política de Transformación Productiva (PTP) y el Sistema Administrativo para la Competitividad (SNC), han transformado a las zonas francas en un instrumento impulsador de la dinamización de la economía, estas han contribuido en un gran porcentaje a la balanza superavitaria que ha tenido el país en los últimos años.

En el nivel meta se observa que las zonas francas son una locomotora de desarrollo no solo en materia económica sino política y social. Para que las zonas francas en el país crezcan se ha implementado por parte del Gobierno Nacional numerosas acciones, las cuales también han impulsado desarrollos en otras áreas que complementan al régimen franco. Se destacan los acuerdos comerciales realizados con diversos países y la disminución en la incertidumbre empresarial, que ha generado un aumento en la inversión extranjera directa.

El marco normativo de las zonas francas en Colombia debería llegar a un punto donde sea tan competitivo como en otros países, específicamente Costa Rica, Estados Unidos, Emiratos Árabes Unidos, China, entre otros, cuyos regímenes generan incentivos en materia fiscal, adecuada infraestructura, innovación tecnológica, la posibilidad de asociación con empresas del mismo sector o de servicios complementarios, así como la generación de encadenamientos productivos, no solo a nivel local sino también internacional, pero principalmente, agilidad en tramitología, con el fin de impulsar el establecimiento de empresas ya sean locales o extranjeras dentro de sus zonas francas, y a su vez crear controles que permitan el adecuado monitoreo de resultados. Es importante señalar que los inversionistas buscan una excelente infraestructura, el no pago de impuestos y protección a la propiedad intelectual.

Finalmente, para que se cumplan las disposiciones realizadas por el Gobierno Nacional mencionadas en el apartado de Nuevos Competidores, referidos a que "se determinó que por el momento no se aprobaría nuevas zonas, hasta que las existentes en el país no se desarrollen completamente y no tengan el nivel de ocupación óptimo", debe procurarse que las zonas francas declaradas ejerzan presión de manera conjunta para que efectivamente se cumpla.

\section{REFERENCIAS BIBLIOGRÁFICAS}

Alvarado, I. J., Méndez, J. C. (2008). Plan de negocio para la creación de la Zona Franca Permanente de la Sabana[Trabajo de Grado de Administración de Empresas]. Universidad Pontificia Javeriana, Facultad de Ciencias Económicas y Administrativas, Bogotá D.C..

Banco Mundial. (2008). Reporte Doing Business en Colombia. Washington, D.C.

Comisión Intersectorial de Zonas Francas (CIZF). Informe zonas francas 2007 - 2012. Octubre 3 de 2012.

Consejo Privado de Competitividad, Universidad 
del Rosario. (2013). Índice Departamental de Competitividad 2013. Bogotá.

Correa, K. A., Bustamante, M., Toro, L. M. (2006). Implicaciones de la Política Tributaria en las Zonas Francas de Colombia.[Trabajo de Grado en Especialización en Políticas y Legislación Tributaria]. Universidad de Medellín, Facultad de Ciencias Económicas y Administrativas, Medellín.

Departamento Nacional de Planeación. (2012). Anuario de Competitividad Mundial. Institute for Management Development - IMD. Resultados para Colombia - 2012. Bogotá.

Departamento Nacional de Planeación. (2012). Reporte Global de Competitividad 2012-2013. Foro Económico Mundial. Síntesis de resultados para Colombia. Bogotá.

Esser, K., Hillebrand, W., Messner, D., Meyer-Stamer, J. Competitividad Sistémica. Disponible e $n$ : journal.ufsc.br/index.php/economia/article/downl oad/6235/5897. [Consultado el 23 de mayo de 2013].

Fernández, M. D., Mejía, L. (2010) Plan de negocio para el montaje de una zona franca permanente especial en servicios de salud. Bucaramanga.[ Trabajo de Grado]. Universidad Industrial de Santander, Escuela de Estudios Industriales y Empresariales, Facultad de Ingenierías Físico-Mecánicas, Bucaramanga.

Forero, D., Rojas, N., Steiner, R. (2012). Resumen del trabajo titulado "Los limitantes al crecimiento en Colombia: una mirado macroeconómica". Bogotá, FEDESARROLLO.
Ley 1004 de 30 de Diciembre de 2005. Bogotá: Congreso de Colombia.

Ministerio de Comercio, Industria y Turismo. Proyecto de decreto por el cual se modifica el régimen de zonas francas Disponible en: http://www.mincit.gov.co/descargar.php?id=6631 3. [Consultado el 18 de noviembre de 2013].

Ministerio de Hacienda y Crédito Público. Decreto 4051 de 2007. Tipos de usuarios de las Zonas Francas. En Diario del Otún. Fecha:14-10-07: 14.

Ortiz, F. G., García, M. P.(2012). Metodología de la investigación: el proceso y sus técnicas. México, DF: Editorial Limusa.

Pahón, E. Zonas Francas no necesitan competencia. Disponible en: http://www.eldiario.com.co/seccion/ECONOMICA/z onas-francas-no-necesitan-competencia-110712. html. [Consultado el 31 de agosto 18 de 2013].

Porter, M.(1980). Competitive Strategy: Techniques for Analyzing Industries and Competitors. The Free Press, New York, 1980:4.

Porter, M.(2008). Las cinco fuerzas competitivas que le dan forma a la estrategia. Harvard Business Review, 86(1), 58 - 77.

Porter, M.(1991). Ventaja Competitiva: Creación y Sostenimiento de un Rendimiento Superior. Buenos Aires: Editorial Rei Argentina s.a.

Zona Franca Internacional de Pereira. Quiénes Somos. Disponible en: http://zonafrancapereira.com/content/somos. [Consultado el 3 de mayo de 2013]. 